\title{
Minimization of magnetoacoustic resonant tags for the electronic article surveillance system
}

\author{
Mariusz Świderski ${ }^{1, *}$, Adam Gulczyński ${ }^{1}$, Jerzy Biernacki ${ }^{2}$ \\ ${ }^{1}$ Faculty of Electrical Engineering, Poznan University of Technology, Poznan, Poland \\ ${ }^{2}$ Complex - System, Poznan, Poland
}

\begin{abstract}
The areas of application of EAS systems are, among others, stores and libraries. EAS systems are used to signal a theft of goods. The exemplary EAS system consists of: a transmitting antenna, a receiving antenna and tags also called clips. The tag is an element of the system with which the consumer has direct contact. The tag can be installed on various items available in the store. Starting from the size of a pen, through jackets and coats to TVs and bicycles. Therefore, the aesthetics, and mainly the size of the tag, cannot distort the consumer's ability to check an item accurately, nor can they affect its use. The paper presents a method of minimizing the dimensions of a tag while maintaining the required detection distance.
\end{abstract}

\section{Electronic Article Surveillance}

The EAS system is shown in Figure 1. Transmitting and receiving antennas are mounted at the exit of the protected zone in which protected goods with attached tags are located. Employees of the protected zone deactivate or remove tags when the item is properly purchased or rented. Otherwise, an alarm will be triggered when an active tag is near antennas [1].

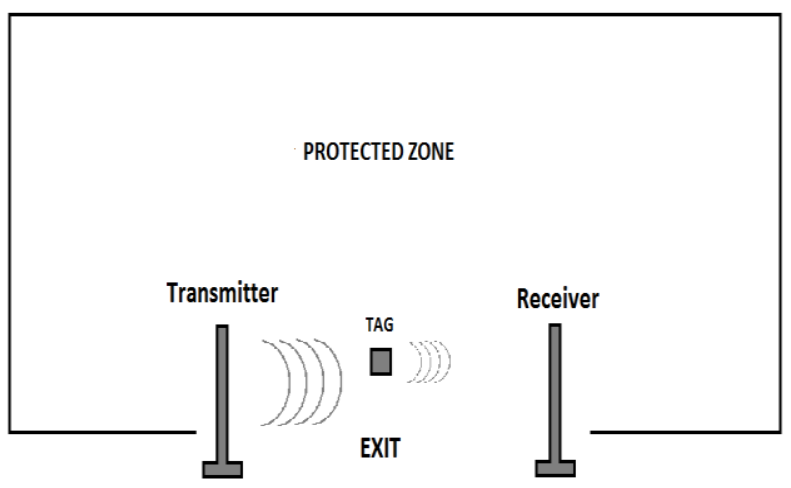

Fig. 1. Electronic Article Surveillance.

In the AM system, antennas have a relatively narrow band, around $600 \mathrm{~Hz}$, and transmit a signal at $58 \mathrm{kHz}$ [2]. The clip is made of a classic coil wound on a core and a capacitor. In contrast, labels are made of magnetostrictive material, this material shrinks under the influence of a magnetic field and a mechanical resonance occurs. The advantage of the AM system is the ability to activate or deactivate label by magnetising or demagnetizing ferromagnetic material contained in it. Deactivation does not damage a label.

\section{Development of a reduced tag for the magnetoacoustic EAS}

Two tag were tested for the detection distance and the results are shown in the graph (Fig. 2).

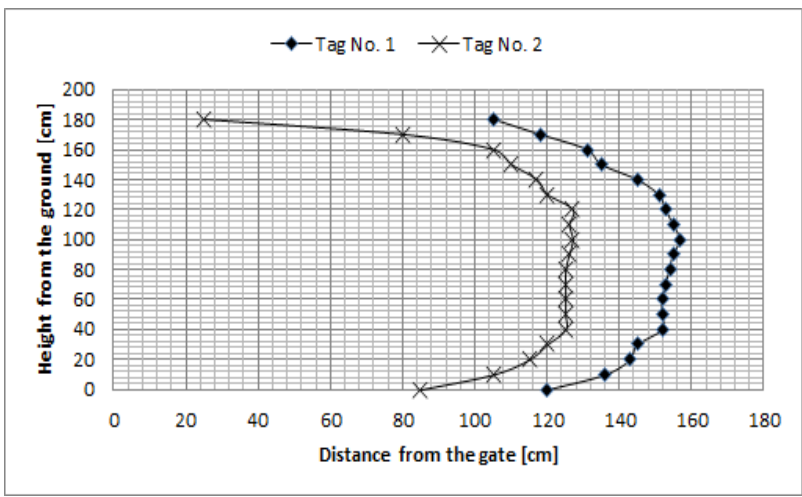

Fig. 2. Characteristics of the maximum distance between a tag and a gate at which a tag is detected.

The design of tag for the magnetoacoustic system was investigated. The resonant circuit consists of a coil wound on a core and a capacitor. The system is an LC resonant circuit. Measurements of electronic components and calculations of resonant circuit parameters were made. The results of measurements and calculations are given in Table 1.

The assumed accuracy of $\mathrm{L}$ and $\mathrm{C}$ components at the level of $0.5 \%$ results in the accuracy of the resonant frequency at the level of $0.5 \%$, and thus the resonance frequency of the tags belongs to the antenna band.

\footnotetext{
* Corresponding author: mariusz.swiderski@put.poznan.pl
} 
Table 1. Parameters of tags for the magnetacoustic system.

\begin{tabular}{|l|c|c|c|}
\hline Parameter & Tag No. 1 & Tag No. 2 & Unit \\
\hline Inductance of the coil & 7.38 & 4.43 & $\mathrm{mH}$ \\
\hline Coil resistance & 18.11 & 10.64 & Ohm \\
\hline Capacitor capacitance & 1 & 1.77 & $\mathrm{nF}$ \\
\hline Number of coils & 450 & 450 & - \\
\hline The length of the winding wire & 10.8 & 7.7 & $\mathrm{~m}$ \\
\hline Permanence AL & 36.44 & 21.09 & $\mathrm{nH}$ \\
\hline The length of the core & 39 & 28 & $\mathrm{~mm}$ \\
\hline diameter of the core & 6 & 4 & $\mathrm{~mm}$ \\
\hline The length of the carcass & 28 & 15 & $\mathrm{~mm}$ \\
\hline The diameter of the carcass & 7 & 5 & $\mathrm{~mm}$ \\
\hline Cross-section of winding wire & 0.0103 & 0.0124 & $\mathrm{~mm} 2$ \\
\hline Resonance frequency & 58.59 & 57.89 & $\mathrm{kHz}$ \\
\hline Goodness of the coil & 149.98 & 146.00 & - \\
\hline Bandwidth & 390 & 400 & $\mathrm{~Hz}$ \\
\hline
\end{tabular}

\section{Implementation of the resonant tag}

The overview of magnetic materials was conducted and cores for building prototypes of tags were selected.

Due to the fact that available capacitor capacitance values are determined by series of types, another method for determining tag parameters has been proposed. For selected cores and for available capacitance values, the required inductance, the number of turns and the required winding resistance were determined, according to the formulas below.

Coil inductance:

$$
L=\frac{1}{\left(2 \pi f_{0}\right)^{2} C} .
$$

where: $\mathrm{f}_{0^{-}}$resonant frequency, $\mathrm{C}-$ capacitor capacity. Number of turns:

$$
n=\sqrt{L / A_{L}},
$$

where: $\mathrm{A}_{\mathrm{L}}$ - core permeability.

Required coil winding resistance:

$$
R=\frac{2 \pi f_{0} L}{Q} .
$$

where: Q - Required Q factor of the resonant circuit.

Selected examples of experimental designs of tags are shown in Figure 3.
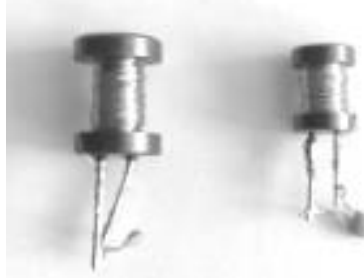

Fig. 3. Sample experimental designs tags.

The results obtained using the second method of

\begin{tabular}{|c|c|c|c|c|c|}
\hline \multirow{5}{*}{ Core } & Name & & R-18 & RS9 & RS8 \\
\hline & Length & $\mathrm{mm}$ & 19 & 12 & 10 \\
\hline & Diameter & $\mathrm{mm}$ & 4 & $9 / 4 / 9$ & $8 / 4 / 8$ \\
\hline & Material & & $\mathrm{nn}$ & AN65H & AN65H \\
\hline & Permeance & $\mathrm{nH}$ & 14.815 & 41.500 & 36.600 \\
\hline \multirow{3}{*}{$\begin{array}{l}\text { Winding } \\
\text { wire }\end{array}$} & Diameter & $\mathrm{mm}$ & 0.125 & 0.09 & 0.09 \\
\hline & Section & $\mathrm{mm} 2$ & 0.0123 & 0.00636 & 0.00636 \\
\hline & $\begin{array}{l}\text { Resistance } \\
\text { of the coil }\end{array}$ & Ohm & 0.0236 & 0.0414 & 0.0408 \\
\hline \multirow{4}{*}{$\begin{array}{l}\text { Tag } \\
\text { parameters }\end{array}$} & $\mathrm{n}$ & & 657 & 411 & 459 \\
\hline & $\mathrm{L}$ & $\mathrm{mH}$ & 6.39 & 7.02 & 7.70 \\
\hline & $\mathrm{C}$ & $\mathrm{nF}$ & 1.17 & 1.07 & 0.97 \\
\hline & $\mathrm{R}$ & Ohm & 15.52 & 17.06 & 18.72 \\
\hline \multirow{5}{*}{ Core } & Name & & RW3/15 & $\mathrm{RW} 2 / 13$ & $\begin{array}{c}\text { RW- } \\
4.0 \times 20 \\
\end{array}$ \\
\hline & Length & $\mathrm{mm}$ & 15 & 13 & 20 \\
\hline & Diameter & $\mathrm{mm}$ & 3 & 2 & 4 \\
\hline & Material & & AN25H & $\mathrm{AN} 25 \mathrm{H}$ & E2D \\
\hline & Permeance & $\mathrm{nH}$ & 21.400 & 14.330 & 22.600 \\
\hline \multirow{3}{*}{$\begin{array}{l}\text { Winding } \\
\text { wire }\end{array}$} & Diameter & $\mathrm{mm}$ & 0.1 & 0.1 & 0.1 \\
\hline & Section & $\mathrm{mm} 2$ & 0.00785 & 0.00785 & 0.00785 \\
\hline & $\begin{array}{l}\text { Resistance } \\
\text { of the coil }\end{array}$ & Ohm & 0.0307 & 0.0209 & 0.0368 \\
\hline \multirow{4}{*}{$\begin{array}{l}\text { Tag } \\
\text { parameters }\end{array}$} & $\mathrm{n}$ & & 591 & 603 & 670 \\
\hline & $\mathrm{L}$ & $\mathrm{mH}$ & 7.48 & 5.21 & 10.16 \\
\hline & $\mathrm{C}$ & $\mathrm{nF}$ & 1.01 & 1.45 & 0.74 \\
\hline & $\mathrm{R}$ & Ohm & 18.17 & 12.66 & 24.67 \\
\hline
\end{tabular}
parameters selection are presented in Table 2 .
Table 2. Calculations of parameters for tags.

\section{Summary}

As part of the research, tests of electromagnetic and functional properties of tags designed for the AM system were performed based on currently available components. A mathematical model of the AM tag was developed and requirements for project purposes were defined. During laboratory work, experimental designs of selected AM tags were made and their tests were performed. Research confirms the thesis that there is the possibility of minimizing the tag.

\section{References}

1. Notes on Inductive RFID.

https://www.coursehero.com/file/10179378/Notes-

on-Inductive-RFID/

2. Electronic article Surveillance,

https://en.wikipedia.org/wiki/Electronic_article_sur veillance

3. K. Finkenzeller, RFID Handbook, 3rd ed. Oxford: Clarendon, 2010, pp.47-77.

4. J. Rathod, B. Bhumi, A Comparative Study of Electronic Article Surveillance (EAS) System., At International Conference on Signals, Systems \& Automation (ICSSA-11), 2011. 